\title{
Árvores nos Salmos: elementos para uma educação espiritual e ambiental
}

\section{Trees in the Psalms: elements for a spiritual and environmental education}

\author{
Matthias Grenzer* \\ PUC-SP \\ Leonardo Henrique Silva Agostinho** \\ PUC-SP
}

Recebido em: 21/05/2021. Aceito em: 12/07/2021.

Resumo: A fé cristã, atenta à palavra de Deus, insiste em relações responsáveis e amorosas entre os seres humanos e, da mesma forma, em relações respeitosas e sustentáveis entre os seres humanos e os animais, vegetais e seres abióticos (água, ar, solo, calor). Visto isso, além de estudar a racionalidade desse tipo de comportamento, favorece-se um esforço espiritual, o qual, há dois milênios, encontra na leitura e oração dos Salmos um norte importante. Surpreende, no entanto, o quanto esses poemas bíblicos, entre outros aspectos, insistem na contemplação da natureza. Ou seja, parece existir uma proposta ecoespiritual nos Salmos que insiste na descoberta da beleza e importância de cada ser, favorecendo-se, assim, uma compreensão mais autêntica do ser humano e de Deus. Para verificar tal hipótese, investiga-se aqui a presença das árvores nos Salmos.

Palavras-chave: Salmos. Árvores. Ecoespiritualidade.

Abstract: The Christian faith, attentive to the word of God, insists on responsible and loving relationships between human beings and, in the same way, on res-

* Doutor em Teologia, Faculdade de Filosofia e Teologia St. Georgen, Frankfurt, Alemanha (1995); Mestre em História, Pontifícia Universidade Católica de São Paulo, PUC-SP (2013); Graduado em Teologia, Faculdade de Filosofia e Teologia St. Georgen Frankfurt, Alemanha (1989). Professor na Faculdade de Teologia da PUC-SP.

E-mail: mgrenzer@pucsp.br

** Graduando em Teologia, Pontifícia Universidade Católica de São Paulo, São Paulo, SP; Graduado em Filosofia, Instituto de Estudos Superiores do Maranhão - Faculdade Católica, IESMA, São Luís, MA (2015).

E-mail: sem.leonardohenrique@yahoo.com.br 
pectful and sustainable relationships between human beings and animals, plants and abiotic beings (water, air, soil, heat). In view of this, in addition to studying the rationality of this type of behavior, a spiritual effort is favored, which, for two millennia, has found an important direction in the reading and prayer of the Psalms. It is surprising, however, how much these biblical poems, among other aspects, insist on the contemplation of nature. In other words, there seems to be an eco-spiritual proposal in the Psalms that insists on discovering the beauty and importance of each being, thus favoring a more authentic understanding of the human being and of God. To verify this hypothesis, the presence of trees in the Psalms is investigated here.

Keywords: Psalms. Trees. Eco-spirituality.

\section{Introdução}

Os Salmos, livro bíblico formado por cento e cinquenta orações poéticas, refletem, centralmente, sobre Deus e o ser humano. No entanto, de forma marcante, eles também acolhem vegetais e animais, isto é, flora e fauna, além de estarem atentos aos seres abióticos (ar, água, solo e calor). Ou seja, certo biocentrismo se junta ao teocentrismo e antropocentrismo. Ou, com outras palavras, trata-se de textos literário-religiosos que não contemplam o ser humano de forma isolada, mas em sua relação com Deus e, o que talvez seja surpreendente, em relação com os demais seres que lhe fazem companhia neste mundo. Assim, os Salmos visam ao mundo como a uma "casa comum", no qual, em vista da sobrevivência de todos, existem importantes convivências e interdependências. ${ }^{1}$

A fim de investigar os pormenores dessa visão ecoteológica e/ ou ecoespiritual, procura-se, neste estudo, pelos vegetais lenhosos nos Salmos. Quais as árvores neles mencionadas? O que se contempla da existência delas? E o que recebe destaque quando os Salmos visam às relações entre, de um lado, os vegetais lenhosos e, de outro, os seres abióticos, os animais, os seres humanos e Deus? Finalmente, quais são as conotações metafóricas e/ou simbólicas que acompanham as árvores quando estas últimas se tornam imagens para realidades mais amplas, transmitindo um saber específico a quem as contempla ao rezar com os Salmos? $?^{2}$

1 Sobretudo a partir da publicação da Carta Encíclica Laudato Si' sobre o cuidado da casa comum, o Papa FRANCISCO (São Paulo: Paulinas, 2015), de forma ímpar, chama a atenção da humanidade para essa realidade.

2 A pesquisa aqui apresentada procura dar continuidade a outros estudos recentemente publicados, os quais, de forma semelhante, acolhem as dimensões ecoteológicas e/ou ecoespirituais presentes nos textos da Bíblia Hebraica: cf. 
Enfim, ao olhar para a Campanha da Fraternidade prevista para 2022, sendo que a Igreja Católica propõe uma reflexão aprofundada sobre a educação, procura-se aqui por elementos bíblicos que, eventualmente, possam favorecer uma educação espiritual e ambiental. Vale, pois, para o comportamento do ser humano que este, em geral, depende da motivação da pessoa, ou seja, daquilo em que esta põe a sua fé. Por isso, a Teologia se dedica a tarefa de estudar tal fé de forma crítica. Afinal, vale para a fé cristã que esta jamais opta por um subjetivismo irracional, mas pela exposição da racionalidade, ou seja, da sabedoria e da inteligência do que é crido.

\section{1 Árvores específicas}

Os Salmos mencionam diversos nomes de espécies de árvores e/ou gêneros de árvores. Junto a isso, os nomes de algumas essências aludem a árvores específicas, porque delas são extraídas. Todavia, a Bíblia não reflete sobre os vegetais lenhosos de acordo com as categorias taxonômicas da Biologia moderna. Antes, "os vocábulos hebraicos nascem dos contextos vitais dos israelitas". ${ }^{3}$ Ou seja, parte-se, inicialmente, do olhar para as regiões geográficas, nas quais determinadas árvores, de acordo com o clima e o solo, encontram condições para sua existência. Com isso, por sua vez, observa-se também o quanto tais vegetais lenhosos oferecem, ora ao ser humano, ora aos animais, espaços e materiais importantes em vista da sobrevivência deles: madeira de construção, vime, lenha, alimentos, essências aromáticas e/ou medicinais, refúgio e sombra. Sejam abordadas, primeiramente, essas dimensões ligadas à existência biológica e à utilidade das árvores.

GRENZER, Matthias; RAMOS, Marivan Soares. Água nos Salmos. Elementos para uma ecoespiritualidade. Revista Eclesiástica Brasileira, v. 80, p. 750-763, 2020; GRENZER, Matthias; BARROS, Paulo Freitas; DANTAS, José Ancelmo Santos. Pássaros nos Salmos. Elementos para uma ecoespiritualidade. In: Revista Eclesiástica Brasileira, 2021 (no prelo); GRENZER, Matthias. Erva, bovino selvagem, tamareira e cedro. Ecoespiritualidade no Salmo 92. In: Atualidade Teológica, v. 24, p. 66-86, 2020; GRENZER, Matthias; GROSS, Fernando. Leis deuteronômicas favoráveis à preservação de fauna e flora. In: Pistis \& Praxis: Teologia e Pastoral, v. 11, p. 778-791, 2019; GRENZER, Matthias. Econarratividades exodais. A praga das rãs em Ex 7,26-8,11. In: SBARDELOTTI, Emerson; GUIMARÃES, Edward; BARROS, Marcelo (org.). Teologia(s) da Libertação. Memória, revisão, perspectivas e desafios. Curitiba: Kotter, 2021 (no prelo).

3 LOSSAU, Victor. Einleitung. In: HÄUSL, Maria (org.). Vom Garten Eden bis zu Salomos Weinberg. Pflanzen der Bibel. Stuttgart: Katholisches Bibelwerk, 2018. p. 13. 


\section{1 Árvores florestais}

Três árvores mencionadas no livro dos Salmos pertencem aos vegetais lenhosos que formam bosques, matas ou selvas. Muitas vezes, trata-se de regiões montanhosas, consideradas perigosas.

O primeiro delas é o cedro (ארז), árvore seis vezes mencionada no livro dos Salmos (S1 29,52x; 80,11; 92,13; 104,16; 148,9). Nos demais escritos da Bíblia Hebraica, o cedro recebe outras sessenta e sete menções. O cedro existia, sobretudo, no Líbano e na Cilícia, mas não em Israel, por crescer em regiões montanhosas, sobre solos rochosos. Com sua altura de trinta a cinquenta metros e com um diâmetro de tronco de até dois metros, o cedro fornece madeira preciosa de construção, sobretudo em vista da resistência dela. No mundo antigo, as diversas nações a importavam para construir navios (Ez 27,5), templos, palácios e móveis ( $2 \mathrm{Sm} 5,11 ; 7,2.7$; 1Rs 5,20.22.24; 6,9.10.15.16.18 ${ }^{2 x} \cdot 20.36 ; 7,2^{2 x} \cdot 3.7 .11 .12 ; 9,11 ;$ Jr 22,14; Ct 1,17; 8,9; Esd 3,7; 1Cr 14,1; 17,1.6; 22,42x; 2Cr 2,2.7), e até ídolos (Is 44,14). Nesse sentido, o cedro se tornou expressão de riqueza (1Rs 10,27 ; Jr 22,15; 2 Cr 1,15; 9,27). Impressiona também como o cedro pode atingir uma idade de até mil anos. ${ }^{4}$ No mais, a madeira do cedro oferece também óleos essenciais, com efeitos antissépticos, bactericidas, diuréticos, expectorantes, fungicidas e inseticidas. ${ }^{5}$ Além disso, conforme as leis de culto no Pentateuco, "a madeira do cedro e/ou as lascas dela eram importantes para ritos de santificação e purificação (Lv 14,4.6.49.51.52; $\mathrm{Nm} 19,6) " .{ }^{6}$ Em vista de tudo isso, compreende-se também que o cedro era objeto de estudo botânico (1Rs 5,13).

Outra árvore florestal uma vez mencionada no livro dos Salmos é

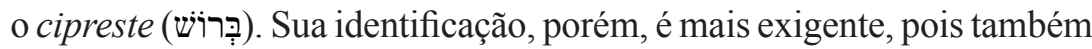
se imagina junípero ou abeto, outras árvores coníferas, como significado do vocábulo hebraico em questão. ${ }^{7}$ Além da menção em S1 104,17, o vocábulo hebraico aparece outras dezenove vezes na Bíblia Hebraica

4 Cf. ASSMANN, Cornelia. Libanon-Zeder. In: HÄUSL, Maria (org.). Vom Garten Eden bis zu Salomos Weinberg. Pflanzen der Bibel. Stuttgart: Katholisches Bibelwerk, 2018, p. 124-125; RIEDE, Peter. Zeder. In: Das wissenschaftliche Bibellexikon im Internet. 2017, p. 1-7. Disponível em: http://www. wibilex.de. Acesso em: 14 maio 2021; ZOHARY, Michael. Pflanzen in der Bibel. 2. ed. Stuttgart: Calwer, 1986. p. 104-105.

5 Cf. ASSMANN, 2018, p. 125; DUKE, James A. Duke's Handbook of Medicinal Plants of the Bible. Boca Raton: CRC Press, 2008. p. 84.

6 RIEDE, 2017, p. 2.

7 Cf. ZOHARY, 1986, p. 106-107. 
(2Sm 6,5; 1Rs 5,22.24; 6,15.34; 9,11; 2Rs 19,23; Is 14,8; 37,24; 41,19; 55,13; 60,13; Ez 27,5; 31,8; Os 14,9; Zc 11,2; 2Cr 2,7; 3,5), sendo que,

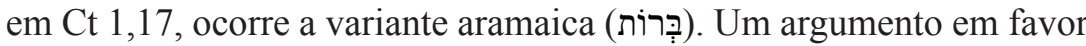
da identificação da árvore como cipreste é que, no levante e, sobretudo, no Líbano, "historicamente, cedro e cipreste eram encontradas nas mesmas regiões, apenas em altitudes diferentes". ${ }^{8} \mathrm{~A}$ isso corresponde que, na Bíblia Hebraica, catorze das vinte menções do cipreste contam com a presença paralela do cedro. Como a madeira deste último, também a madeira do cipreste era preciosa (1Rs 5,24) e, "para cortar" essas árvores era preciso ter homens peritos $(2 \mathrm{Cr} 2,7)$. Todavia, o cipreste fornecia madeira para a construção de navios, isto é, a fabricação dos "conveses" (Ez 27,5), para a construção de templos e palácios, sobretudo para produzir "pranchas a fim de cobrir o piso" (1Rs 6,15), "portas" (1Rs $6,34)$ ou "forrar uma sala, cobrindo a madeira de ouro e gravando nela palmas e cadeias" como ornamentos $(2 \mathrm{Cr} 3,5)$. Além disso, ouve-se de instrumentos musicais feitas de "madeiras de ciprestes" (2Sm 6,5).

\section{2 Árvores em terreno úmido}

Outro nome hebraico de uma árvore ora é bem compreendido como salgueiro, ora como álamo ou choupo (עָרָרָה). Fazendo parte da mesma família, são representantes daqueles vegetais lenhosos que crescem em regiões mais úmidas. Em vista de Israel, é preciso pensar "no vale do Jordão, na planície costeira, nas beiras dos rios e/ou na proximidade de fontes". "A única presença dessa árvore nos Salmos, por sua vez, ocorre "nos rios da Babilônia" (Sl 137,1-2). "Pode tratar-se do choupo-do-eufrates como do salgueiro, uma vez que ambos são abundantes ao longo do Eufrates". ${ }^{10}$

Em toda a Bíblia Hebraica, o "salgueiro" ou "álamo/choupo"

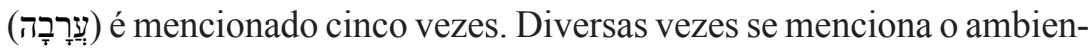
te em que cresce. Fala-se da "torrente" ou do "riacho dos salgueiros" (Is 15,7), sendo que "os salgueiros da torrente" até chegam a "cercar" o hipopótamo (Jó 40,22). Admira-se como "salgueiros" ou "álamos brotam junto a correntes de água" (Is 44,4) para, assim, comparar a eles

8 MUSSELMANN, Lytton John. A Dictionary of Bible Plants. Cambridge: University Press, 2012. p. 47.

9 ZOHARY, 1986, p. 127.

10 MUSSELMANN, 2012, p. 120. 
os descendentes de Israel que, novamente, são equipados com o espírito do Senhor.

No Sl 137, por sua vez, os "salgueiros" ou "álamos", "junto aos rios da Babilônia", se tornam o espaço em que os exilados se "sentam e choram", além de neles "pendurarem suas cítaras" por não quererem cantar "um canto de Sião", isto é, "um canto do Senhor em solo estrangeiro" (v. 1-2). Imaginando o chorão, que é um salgueiro, a forma da árvore parece ganhar algum simbolismo. Como os ramos dele se inclinam para baixo, os exilados também não querem erguer suas cabeças. Em contrapartida, por sua vez, a mesma árvore também é representante da esperança por libertação, quando, por ocasião da festa das cabanas, há a presença do "fruto de uma árvore esplendorosa, palmas de tamareiras e ramagem de uma árvore viçosa e de salgueiros ribeirinhos" (Lv 23,40). No que se refere ao salgueiro, ora os ramos com a inflorescência chamam atenção, ora sua qualidade de vimeiro, sendo que o vime, com sua flexibilidade, é um material precioso para trabalhos trançados.

\section{3 Árvores frutíferas}

Os frutos produzidos por determinados vegetais lenhosos são uma das mais importantes fontes de alimentação para o ser humano. Com isso, o cultivo de árvores frutíferas é uma arte milenar. Os Salmos mencionam cinco espécies desse grupo tão especial entre os vegetais lenhosos.

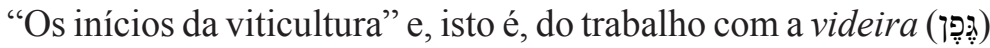
"remontam ao terceiro milênio antes de Cristo, tanto no Egito como no Oriente Próximo". ${ }^{11} \mathrm{O}$ vegetal encontra cinquenta e cinco menções em toda a Bíblia Hebraica, sendo cinco delas no livro dos Salmos (S1 78,47; $80,9.15 ; 105,33 ; 128,3)$. Além disso, os vocábulos hebraicos comumente traduzidos como "vinha (כֶּרֶ), (S1 107,37), "vinho novo (S1 4,8) e "vinho (י!-)" (Sl 60,5; 75,9; 78,65; 104,15) são mencionados no livro bíblico em questão, enquanto outras palavras pertencentes ao mesmo

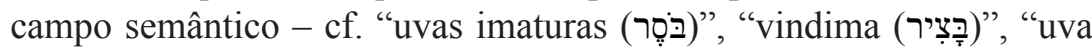

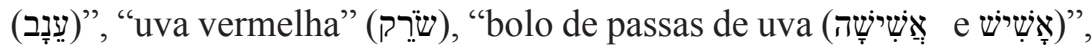

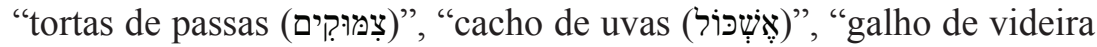

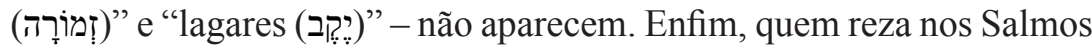

11 LOSSAU, Victor. Echter Wein - Das Volk Gottes. In: HÄUSL, Maria (org.). Vom Garten Eden bis zu Salomos Weinberg. Pflanzen der Bibel. Stuttgart: Katholisches Bibelwerk, 2018. p. 111. 
contempla, de um lado, os diversos trabalhos que o viticultor realiza com a videira: esta, eventualmente "arrancada" de outro lugar, precisa ser "plantada" (S1 80,9.16), para depois ser "cuidada" (S1 80,15), no sentido de ser "firmada" (S1 80,16). Ao contrário, ela não produziria e seria "queimada no fogo" (Sl 80,16). Como "videira fecunda" (S1 128,3), porém, ela se torna imagem para a "mulher que almeja ser mãe e que se abre à maternidade", aproximando esta última "da aliança do Senhor com seu povo". ${ }^{12}$ De outro lado, o orante nos Salmos sabe dos perigos que ameaçam a videira: entre eles, o "granizo" (S1 78,47; 105,32), "chamas de fogo" (S1 105,32), o "gafanhoto" e o "grilo" (S1 105,34). O quanto o trabalho humano e as catástrofes naturais em relação à videira e às demais árvores ganham conotações religiosas será estudado mais tarde.

A oliveira (II) é outro vegetal lenhoso que acompanha a civilização humana desde os seus inícios. No caso, o vocábulo hebraico indica tanto o vegetal e o fruto produzido por ele, isto é, as azeitonas. Duas das trinta e oito presenças da árvore em questão estão nos Salmos (S1 52,10; 128,3). Além disso, o "azeite (שֶָׁ)", tão importante como alimento e como base para os perfumes, está dez vezes presente (S1 $23,5 ; 45,8 ; 55,22 ; 89,21 ; 92,11 ; 104,15 ; 109,18.24 ; 133,2 ; 141,5)$, ao

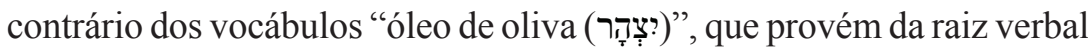
"espremer azeite (צהר)" (Jó 24,11), e "lagar (יצרבי:)" (Jl 2,24). Todavia, o fato de o orante nos Salmos comparar-se a "uma oliveira frondosa na casa de Deus" (S1 52,10) e contemplar e os "filhos" do homem temente a Deus a "rebentos de oliveiras" (S1 128,3) revela o quanto esse vegetal lenhoso é valorizado na cultura do Israel bíblico. Enfim, vinho e azeite, produzidos pela videira e oliveira, são dois dos três alimentos básicos. Falta somente o pão que, sobretudo, é feito dos grãos produzidos pelo trigo e pela cevada, que são vegetais herbáceos.

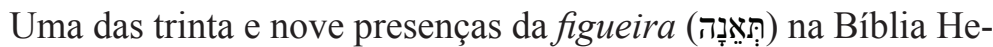
braica ocorre no S1 105,33. Em nenhum momento, porém, os Salmos

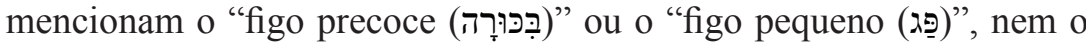
"bolo de figo (דָרָּרָה)". "Escavações" no Levante indicam a existência de "figos secos já em torno de 5000 antes de Cristo". ${ }^{13}$ "A figueira jovem é de crescimento rápido e, após três a sete anos, oferece os primeiros frutos",

12 FERNANDES, Leonardo Agostini. O Salmo 128 e a alegria do amor. In: FERNANDES, Leonardo Agostini (org.). Amoris Laetitia em questão: Aspectos bíblicos, teológicos e pastorais. São Paulo: Paulinas, 2018. p. 21.

13 ZOHARY, 1986, p. 58. 
isto é, "com oitenta a cem quilogramas de frutos por ano, a figueira é especialmente rentável". ${ }^{14}$ Embora "sentar debaixo da figueira", em princípio, simbolize uma vida "sem susto" ou "sobressalto", de acordo com "a palavra do Senhor" (Mq 4,4), o orante nos Salmos, contrariamente, sabe da possibilidade de "a figueira ser ferida": "granizo", "fogo", "gafanhoto", "grilo" (S1 105,32-34) ou também a ação belicosa de "cercar uma cidade" (Dt 20,19-20) podem ameaçar a existência desse vegetal lenhoso. ${ }^{15}$ Enfim, bem-estar ou vida doce, representados pela figueira, é algo delicado que o homem, por conta própria, não garante.

Outra árvore frutífera uma vez mencionada nos Salmos é o sicômo-

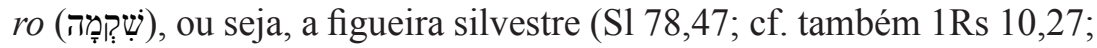
$1 \mathrm{Cr} 27,28 ; 2 \mathrm{Cr} 1,15 ; 9,27$; Is 9,9; Am 7,14). Cabem-lhe diversas utilidades: "a copa larga, com uma extensão de vinte a vinte cinco metros", ${ }^{16}$ oferece uma "sombra bem-vinda nas praças dos vilarejos"; sua "madeira mais comum e barata é procurada para as construções e, por causa de seu peso menor, ideal para as construções de coberturas e tetos" ${ }^{17}$ mas também para a "fabricação de móveis, estátuas, navios e sarcófagos", além de "a seiva leitosa da casca" servir como "medicina"; ${ }^{18}$ embora menos doces do que os verdadeiros figos, seus frutos são comestíveis, sendo que, para acelerar o processo de amadurecimento, são riscados com uma faca redonda (Am 7,14). Quem reza nos Salmos também contempla o "sicômoro" como vegetal lenhoso que pode sofrer a "morte", caso, por exemplo, seja atingido por "pedras de gelo" ou uma "chuva desastrosa" (S1 78,47).

Resta a tamareira (תֶָָ๊), outra árvore frutífera antiga. Comprovadamente, ela já foi cultivada no Egito e na Mesopotâmia desde 5000 a.C. A tamareira atinge uma altura de dez a trinta metros. No extremo do caule, forma-se um tufo com até vinte folhas pinadas de dois a três metros. Entre os seus trinta e cem anos, a árvore produz, anualmente,

14 SWARS, Theresia. Echte Feige. In: HÄUSL, Maria (org.). Vom Garten Eden bis zu Salomos Weinberg. Pflanzen der Bibel. Stuttgart: Katholisches Bibelwerk, 2018. p. 82.

15 Cf. GRENZER; GROSS, 2019, p. 786-788.

16 ZOHARY, 1986, p. 68.

17 LOSSAU, Victor. Maulbeer-Feige - Bescheidenheit. In: HÄUSL, Maria (org.). Vom Garten Eden bis zu Salomos Weinberg. Pflanzen der Bibel. Stuttgart: Katholisches Bibelwerk, 2018. p. 97.

18 SCHMELTER, Denis. Maulber-Feige. In: HÄUSL, Maria (org.). Vom Garten Eden bis zu Salomos Weinberg. Pflanzen der Bibel. Stuttgart: Katholisches Bibelwerk, 2018. p. 100. 
até cem quilogramas de tâmaras, bagos carnudos de dois a sete centímetros com amido e um porcentual alto de açúcar. Além da produção desse alimento precioso, a tamareira oferece sua madeira como lenha e material de construção, suas folhas para a confecção de tapetes, cestos e outros utensílios, assim como suas fibras que, misturadas com pelos de animais, servem para fazer cordas e lonas. ${ }^{19} \mathrm{O}$ nome hebraico do vegetal lenhoso - ver a "tamareira (תฺָָָ )" em Ex 15,27; Lv 23,40; Nm 33,9; S1 92,13; Ct 7,8.9; Jl 1,12; Ne 8, 15 e, com outra vocalização diferente (רֶุ่) em Jz 4,5; Jr 10,5 - também existe como nome próprio de mulher (ver

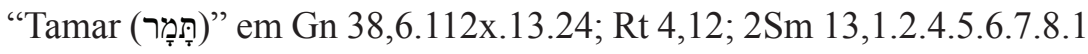
$\left.0^{2 x} \cdot 19.20 .22 .32 ; 14,27 ; 1 \mathrm{Cr} 2,4 ; 3,9\right)$ e de local (ver Jericó como "cidade das tamareiras" em Dt 34,3; Jz 1,16; 3,13; 2 Cr 28,15, ou "Tamar" em 1Rs 9,18; Ez 47,19; 48,28). Além disso, prevê-se o uso de "ramos" ou "folhas de tamareiras" para a festa das cabanas ( $\operatorname{Lv} 23,40 ; \mathrm{Ne} 8,15)$. No livro dos Salmos, por sua vez, o orante valoriza as características da árvore em questão para afirmar que "o justo floresce como a tamareira", além de "crescer como o cedro do Líbano" (S1 92,13).

\section{4 Árvores produtoras de essências aromáticas}

Em S1 45,8-9, "Deus unge" o rei de Israel com "perfume de festim", sendo que "as roupas dele estão com mirra, aloés e acácias" (S1 45,8-9). Trata-se de três substâncias aromáticas produzidas por árvores.

O substantivo mirra (מל) é mencionado doze vezes na Bíblia Hebraica (Ex 30,23; Est 2,12; Sl 45,9; Pr 7,17; Ct 1,13; 3,6; 4,6.14; $5,1.5^{2 x} .13$ ) e indica uma "resina, ingrediente do óleo santo e cosmético, sendo que, na antiguidade, tal substância aromática é um perfume procurado, além de existir o uso medicinal". ${ }^{20}$ São o tronco e os galhos da comífora que oferecem o líquido precioso. $\mathrm{O}$ vegetal lenhoso, por sua vez, somente existe "no norte da África, na Arábia e na Índia". ${ }^{21}$ Por isso, no tempo do Israel bíblico, a mirra é um produto importado.

19 RIEDE, Peter. Palme. In: Das wissenschaftliche Bibellexikon im Internet. 2018, p. 1-7. Disponível em: http://www.wibilex.de. Acesso em: 14 maio 2021; SCHÜTTE, Inga Maria. Dattelpalme. In: HÄUSL, Maria (org.). Vom Garten Eden bis zu Salomos Weinberg. Pflanzen der Bibel. Stuttgart: Katholisches Bibelwerk, 2018. p. 77-78; ZOHARY, 1986, p. 60-61.

20 ZOHARY, 1986, p. 200.

21 MUSSELMANN, 2012, p. 96. 


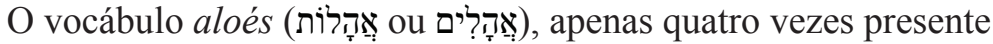
na Bíblia Hebraica (Nm 24,6; S1 45,9; Pr 7,17; Ct 4,14), indica a árvore e/ou o "perfume precioso" extraído da madeira, isto é, do pau-de-águila de árvores do gênero aquilária. ${ }^{22}$ Trata-se novamente de um material importado do leste da África ou do norte da Índia. Diferente desse extrato existe também o aloés da aloé vera, conhecida por babosa, que, em Jo 19,39-40, é mencionado como especiaria aromática no sepultamento de Jesus. $^{23}$

Além disso, Sl 45,9, aparentemente, conhece também o óleo da

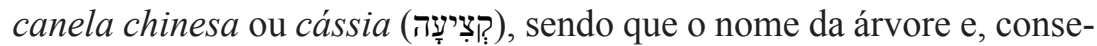
quentemente, do perfume precioso é atestado como nome de mulher (Jó 42,14). "Frascos com restos de óleo de canela em sítios arqueológicos do período de ferro, encontrados em espaços de templos e tesouros (por exemplo, em Dor, Kinneret e Meguido), sugerem a hipótese de que seu conteúdo era precioso e, por isso, usado em cultos e cerimônias". ${ }^{24}$ Além

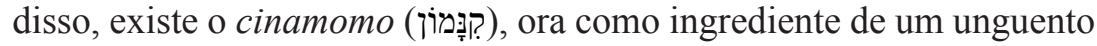
sagrado (Ex 30,23), ora como perfume ( $\operatorname{Pr} 7,17$; Ct 4,14), o qual é extraído da casca da canela verdadeira. Ambas as especiarias são produtos importados no Israel bíblico.

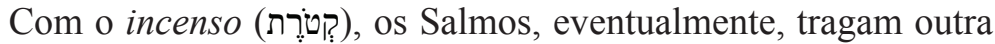
referência a vegetais lenhosos. Além da nuvem odorante resultado da queima de um animal, como o "incenso de carneiros" (S1 66,15), há incensos vegetais. No caso, a arqueologia estuda utensílios usados para tais incensos, ora pequenos recipientes redondos com furos laterais, em forma de "tigelas" sobre pés, ora "caixinhas" quadriculadas, ora "altares" pequenos com uma superfície não suficientemente grande para a oferta de um animal. ${ }^{25}$ Nesse caso, o "incenso", representante da "oração firme diante do Senhor" (S1 141,1-2), inclui ingredientes como

22 LOSSAU, Victor. Echte Aloé - Der Geruch der Unsterblilchkeit. In: HÄUSL, Maria (org.). Vom Garten Eden bis zu Salomos Weinberg. Pflanzen der Bibel. Stuttgart: Katholisches Bibelwerk, 2018. p. 49.

23 Cf. GRENZER, Matthias; GRENZER, Francisca Antonia de Farias. Especiarias aromáticas no sepultamento de Jesus (João 19,39-40). In: Paralellus, v. 9, p. 35-47, 2018.

24 VÖGELI-PAKKALA, Christine. Speise/Speisezubereitung. In: Das wissenschaftliche Bibellexikon im Internet. 2018, p. 12. Disponível em: http://www.wibilex.de. Acesso em: 14 maio 2021.

25 BECHMANN, Ulrike. Duft im Alten Testament. In: KÜGLER, Joachim (org.). Die Macht der Nase. Zur religiösen Bedeutung des Duftes. Religionsgeschichte - Bibel - Liturgie. Stuttgart: Katholisches Bibelwerk, 2000. p. 50-53. 
o "olíbano (לְבְָָּ)" (Ex 30,34), uma "resina extraída dos arbustos do gênero boswellia". ${ }^{26}$

\subsection{Arbustos fornecedores de combustíveis}

O ser humano precisa ter combustível, sobretudo para cozinhar. No caso, é suficiente usar galhos de arbustos, que, em geral, são vistos como vegetais lenhosos menos preciosos. Assim, uma das orações poéticas no livro dos Salmos menciona "as panelas que sentem o espinheiro (אטָָָ)" (S1 58,10). Embora não seja possível identificar a espécie, a parábola de Joatão deixa claro o quanto o "espinheiro" (Jz 9,14.152x) é inferior à oliveira, figueira e videira. Contudo, o grau de inflamabilidade da madeira desse arbusto é alto, sendo que dele pode "sair um fogo" capaz de "devorar os cedros do Líbano" (Jz 9,15).

Focando na mesma característica, S1 120,4 menciona a "giesta (רִתֶם)". A madeira desse vegetal lenhoso, pois, pode ser transformado em "brasas de fogo" (S1 18,13.14) ou "brasas com fogo" (S1 140,11), isto é, "brasas incendiárias" (S1 18,9). Ou seja, por causa de o material ser candente, "flechas" equipadas com "brasas de giesta" (Sl 120,4), ao serem atiradas para dentro de uma cidade, podem causar estragos enormes.

\section{2 Árvores em geral}

Junto aos nomes específicos de determinados vegetais lenhosos, os Salmos acolhem seis vezes o termo genérico ou o hiperônimo "árvore (עיץ)" (S1 1,3; 74,5; 96,12; 104,16; 105,33; 148,9). Além disso, as orações poéticas em questão contemplam partes desses vegetais - a "folha" ou a

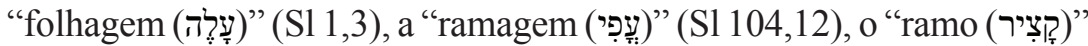

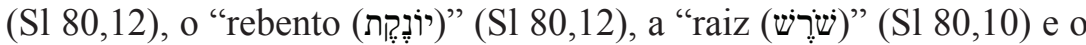
"fruto (פִּרִּר)" (S1 1,3; 107,37; 148,9) -, assim como espaços formados, sobretudo, por árvores e arbustos - a "mata espessa (ס्ִ (S1 74,5) e o "bosque (יעַר)" (S1 29,9; 50,10; 80,14; 83,15; 96,12; 104,20). Ao observar o que é dito nesses momentos, é possível perceber alguns entendimentos no que se refere à existência das árvores.

No caso, distingue-se entre plantas silvestres e plantas de cultura, sendo que as últimas, "no decorrer da história, foram desenvolvidas por

26 RIEDE, Peter. Weihrauch. In: Das wissenschaftliche Bibellexikon im Internet. 2019, p. 1. Disponível em: http://www.wibilex.de. Acesso em: 14 maio 2021. 
meio de criação ou de seleção dentre as plantas selvagens". ${ }^{27}$ Isso, por sua vez, não significa que as plantas selvagens, as quais, no Israel bíblico, têm presença "desde a vegetação do deserto, passando pela estepe, até a terra cultivada", fossem menos importantes para o ser humano e os animais. ${ }^{28}$ No entanto, quem reza nos Salmos sabe da "árvore plantada junto a canais de água, o qual dá seu fruto a seu tempo" (S1 1,3), e/ou dos "famintos" que "plantam vinhas", a fim de colherem "o fruto", isto é, a "produção" dela (S1 107,37). "Plantar", por sua vez, significa realizar diversos trabalhos: ora a "planta" já existente é "arrancada" do lugar em que existia anteriormente, para ela, em outro lugar, após "revirar" a terra "diante dela", "estender suas raízes e encher a terra" (S1 80,9-10). Enfim, assim como os cereais, o homem bíblico cultiva diversas árvores frutíferas, para investir em sua sobrevivência.

Existe também um entendimento em relação à interdependência entre fauna, flora e seres humanos. Ou seja, em diversos momentos, ao contemplar-se um ser da natureza, imediatamente se menciona a relação dele com outros seres. Isso vale em especial para as árvores. Medita-se, no caso, como "as aves moram" e "soltam sua voz entre as ramagens" das árvores (S1 104,12). Além disso, o orante sabe do "animal do bosque" (S1 50,10) e, em especial, do "javali do bosque" (S1 80,14), incluindo-se a percepção de que "o animal do bosque se move à noite" (S1 104,20). O quanto o ser humano é beneficiado pela presença das árvores já ganhou visibilidade nos parágrafos anteriores.

Com isso, parece existir também uma noção a respeito da necessidade de cooperação entre o ser humano e os vegetais lenhosos. Afinal, árvores correm riscos. Tempestades podem "ferir" e "quebrar as árvores" em determinada "região" (S1 105,33), "desnudando bosques" (S1 29,9). Ou um "fogo", com suas "chamas", pode "queimar um bosque" (S1 83,15). Também não podem faltar "cursos de água", para que "as árvores se saciem" com esta última (S1 104,10.16). Outro perigo para a árvore, porém, é justamente o ser humano, isto é, quando este emprega

27 SCHOENBORN, Ulrich; WELTEN, Peter. Kulturpflanzen. In: CRÜSEMANN, Frank; HUNGAR, Kristian; JANSSEN, Claudia; KESSLER, Rainer; SCHOTTROFF, Luise (org.). Sozialgeschichtliches Wörterbuch zur Bibel. Gütersloh: Gütersloher Verlagshaus, 2009a. p. 322.

28 SCHOENBORN, Ulrich; WELTEN, Peter. Wildpflanzen. In: CRÜSEMANN, Frank; HUNGAR, Kristian; JANSSEN, Claudia; KESSLER, Rainer; SCHOTTROFF, Luise (org.). Sozialgeschichtliches Wörterbuch zur Bibel. Gütersloh: Gütersloher Verlagshaus, 2009b. p. 652. 
seus "machados na mata espessa das árvores" e causa destruições amplas $($ S1 74,5).

Resumindo: "a árvore, em geral, é um símbolo de vida e fertilidade". ${ }^{29}$ Aparentemente, "sempre verde" (S1 1,3) e com "folhagem que não murcha" (S1 1,3), ela é capaz de "estender seus ramos até o mar e seus rebentos até o rio" (S1 80,12), a fim de ganhar uma presença ímpar. Além disso, as árvores, sobretudo as mais altas, parecem ligar a terra ao céu. Contudo, este último e alguns dos outros detalhes já mencionados geram a questão sobre as dimensões ecoteológicas e/ou ecoespirituais que, segundo a reflexão promovida nos Salmos, acompanham os vegetais lenhosos.

\section{Deus e as árvores}

O primeiro passo na pesquisa aqui apresentada foi o de conhecer os vegetais lenhosos que as orações poéticas no livro dos Salmos envolvem em sua reflexão espiritual, seja ao mencionar árvores e/ou os arbustos específicos, seja ao refletir sobre as árvores como gênero. No caso, é preciso reconhecer que, na Bíblia Hebraica, Deus, em princípio, é pensado junto a toda a realidade. Evitam-se dualismos, no sentido de não se promover uma separação rígida entre os seres que ocupam este mundo e o Senhor, Deus de Israel. Isto é, a Deus sempre pertence o senhorio absoluto sobre todas as realidades existentes. Além disso, Deus se revela ao ser humano no mundo em que este último vive. Em vista disso, os Salmos propõem uma sabedoria, segundo a qual também as árvores se tornam transparentes para a presença de Deus, estando a serviço dele. Portanto, ao revisitar os paralelismos já mencionados, é colocada agora a pergunta sobre o que os Salmos, mais especificamente, apresentam de reflexão quando visam à relação entre Deus e as árvores.

De forma expressa, as orações bíblicas em questão favorecem a ideia de que as árvores pertencem a Deus. Nesse sentido, lê-se em S1

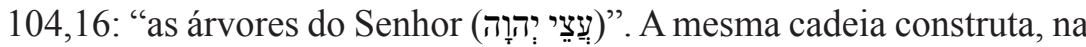
qual, em hebraico, a primeira palavra encosta na segunda e dela recebe

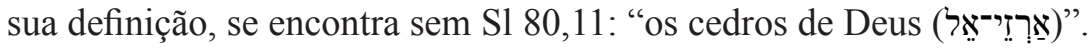
Enfim, indica-se uma relação que, principalmente, é de posse. Favorece-se a ideia de que, como todos os seres, também as árvores, inclusive o

29 MÜLLER TRUFAUT, Susanne. Weltenbaum. In: Das wissenschaftliche Bibellexikon im Internet. 2007, p. 1. Disponível em: http://www.wibilex.de. Acesso em: 14 maio 2021. 
seu representante mais majestoso, são do Senhor, Deus de Israel. Mais ainda, além de serem de Deus, as árvores existem junto a ele. Eis o que a imagem da "oliveira frondosa na casa de Deus" (S1 55,10) transmite.

A partir desse pressuposto, os Salmos imaginam duas atuações de Deus com as árvores. Ora o Senhor é visto como quem "arranca uma videira" e "a planta" em outro lugar, "revirando a terra diante dela" (S1 80,9-10). E o transplante indica o quanto Deus se propõe a "olhar atentamente", "cuidar", "firmar" e "tornar resistente" o vegetal lenhoso que "sua direita planta" (S1 80,15-16). No caso, a videira representa o povo oprimido dos hebreus no Egito. Contudo, ao enfrentar o opressor, a atuação do mesmo Deus com as árvores pode ser contrária. De repente, ele "fere videira e figueira" (Sl 105,33), ou "mata a videira e o sicômoro com granizo e geada" (Sl 78,47). Isto é, a realeza do Senhor, Deus de Israel, o qual insiste na liberdade de quem é brutalmente explorado e visa a convivências mais justas e igualitárias entre os seres humanos, pode ser contemplada também quando ele "desnuda bosques" $(\mathrm{S} 129,9)$ e/ou "destroça cedros" (Sl 29,5). Assim, árvores derrubadas se tornam imagem e mensageiros da força infinita de Deus, muito superior a todos os seres que se elevam nesta terra.

Finalmente, seja contemplado o convite que os Salmos fazem também às árvores. Junto aos demais seres, eles são envolvidos na dinâmica que, ao observar-se a inversão de miséria e sofrimento em bem-estar e sobrevivência digna, prevê a transformação do lamento em louvor. Ou seja, tudo deve culminar num regozijo alegre, sendo que não pode faltar a manifestação dos vegetais lenhosos. Por isso, vale o seguinte convite: "Louvai o Senhor, [...] ó árvore frutífera e todos os cedros" (S1 148,7.9). Ou seja, ao reconhecer-se a realeza do Senhor Deus entre as nações e estas últimas experimentarem a retidão divina, capaz de firmar o mundo e protegê-lo de abalos, estando em pé, "as árvores do bosque irão jubilar" (S1 96,12).

\section{Considerações finais}

As orações poéticas milenares nos Salmos trazem elementos significativos para uma educação espiritual e ambiental. Aparentemente, tais textos bíblicos já se aproximam à visão de uma "ecologia integral". ${ }^{30}$ Deus, o ser humano, fauna, flora e seres abióticos são pensados juntamente, sabendo-se

$30 \quad$ FRANCISCO, 2015, § 138-142. 
de suas existências conjuntas neste mundo. Em especial, contemplam-se as interdependências entre as questões ambientais, sociais, econômicas e, também, religioso-espirituais, no sentido de, "na tradição judaico-cristã, dizer criação é mais do que dizer natureza, porque tem a ver com um projeto do amor de Deus, onde cada criatura tem um valor e um significado". ${ }^{31}$

No caso da pesquisa aqui apresentada, ocorreu uma releitura dos Salmos visando às árvores neles mencionadas. Decerto, vale em relação ao Israel bíblico até o Israel presente, assim como em vista do ser humano no mundo inteiro, que "a história evolutiva do ser humano começa com as árvores e não é possível imaginar um futuro sem elas". ${ }^{32}$ Por causa disso, é preciso tratar os vegetais lenhosos com grande respeito e sempre acompanhado de projetos de sustentabilidade. Mais ainda, vale "lembrar que uma ecologia integral não se dá por satisfeita com ajustes de questões técnicas ou com decisões políticas, jurídicas e sociais", mas "a grande ecologia sempre inclui um aspecto educativo, que provoca o desenvolvimento de novos hábitos nas pessoas e nos grupos humanos". ${ }^{33}$

Em vista disso, favorece-se aqui maior atenção às dimensões ecoespirituais presentes nas orações poéticas acolhidas no livro bíblico dos Salmos. Eis as dicas, aparentemente, presentes nesses textos: no que se refere às árvores, é importante, antes de tudo, conhecê-las. Ou seja, saber de seus nomes, de sua beleza e de seu modo de existir, inclusive de tudo aquilo que tais vegetais lenhosos oferecem ao ser humano para favorecer a sobrevivência dele. Junto a isso, por sua vez, os Salmos também convidam os seus ouvintes-leitores e/ou orantes a descobrirem que as árvores pertencem a Deus, manifestam a palavra de Deus e louvam a Deus. Portanto, quem mexe com uma árvore não atinge apenas um vegetal lenhoso.

\section{Referências}

ASSMANN, Cornelia. Libanon-Zeder. In: HÄUSL, Maria (org.). Vom Garten Eden bis zu Salomos Weinberg. Pflanzen der Bibel. Stuttgart: Katholisches Bibelwerk, 2018. p. 124-125.

31 FRANCISCO, 2015, § 76.

32 TAL, Alon. All the Trees of the Forest. Israel's Woodlands from the Bible to the Present. New Haven; London: Yale University Press, 2013. p. XIV.

33 FRANCISCO, Papa. Exortação Apostólica Pós-Sinodal Querida Amazônia. Brasília: Edições CNBB, 2020. § 58. 
BECHMANN, Ulrike. Duft im Alten Testament. In: KÜGLER, Joachim (org.). Die Macht der Nase. Zur religiösen Bedeutung des Duftes. Religionsgeschichte - Bibel - Liturgie. Stuttgart: Katholisches Bibelwerk, 2000. p. 49-98.

DUKE, James A. Duke's Handbook of Medicinal Plants of the Bible. Boca Raton: CRC Press, 2008.

FERNANDES, Leonardo Agostini. O Salmo 128 e a alegria do amor. In: FRNANDES, Leonardo Agostini (org.). Amoris Laetitia em questão: aspectos bíblicos, teológicos e pastorais. São Paulo: Paulinas, 2018. p. 17-31.

FRANCISCO, Papa. Carta Encíclica Laudato Si' sobre o cuidado da casa comum. São Paulo: Paulinas, 2015.

FRANCISCO, Papa. Exortação Apostólica Pós-Sinodal Querida Amazônia. Brasília: Edições CNBB, 2020.

GRENZER, Matthias. Econarratividades exodais. A praga das rãs em Ex 7,26-8,11. In: SBARDELOTTI, Emerson; GUIMARÃES, Edward; BARROS, Marcelo (org.). Teologia(s) da Libertação. Memória, revisão, perspectivas e desafios. Curitiba: Kotter, 2021 (no prelo).

GRENZER, Matthias. Erva, bovino selvagem, tamareira e cedro. Ecoespiritualidade no Salmo 92. In: Atualidade Teológica, v. 24, p. 66-86, 2020.

GRENZER, Matthias; BARROS, Paulo Freitas; DANTAS, José Ancelmo Santos. Pássaros nos Salmos. Elementos para uma ecoespiritualidade. In: Revista Eclesiástica Brasileira, 2021 (no prelo).

GRENZER, Matthias; GRENZER, Francisca Antonia de Farias. Especiarias aromáticas no sepultamento de Jesus (João 19,39-40). In: Paralellus, v. 9, p. 35-47, 2018.

GRENZER, Matthias; RAMOS, Marivan Soares. Água nos Salmos. Elementos para uma ecoespiritualidade. Revista Eclesiástica Brasileira, v. 80, p. $750-763,2020$.

GRENZER, Matthias; GROSS, Fernando. Leis deuteronômicas favoráveis à preservação de fauna e flora. In: Pistis \& Praxis: Teologia e Pastoral, v. 11, p. 778-791, 2019.

LOSSAU, Victor. Echte Aloé - Der Geruch der Unsterblilchkeit. In: HÄUSL, Maria (org.). Vom Garten Eden bis zu Salomos Weinberg. Pflanzen der Bibel. Stuttgart: Katholisches Bibelwerk, 2018. p. 49-50. 
LOSSAU, Victor. Echter Wein - Das Volk Gottes. In: HÄUSL, Maria (org.). Vom Garten Eden bis zu Salomos Weinberg. Pflanzen der Bibel. Stuttgart: Katholisches Bibelwerk, 2018. p. 111-112.

LOSSAU, Victor. Einleitung. In: HÄUSL, Maria (org.). Vom Garten Eden bis zu Salomos Weinberg. Pflanzen der Bibel. Stuttgart: Katholisches Bibelwerk, 2018. p. 9-17.

LOSSAU, Victor. Maulbeer-Feige - Bescheidenheit. In: HÄUSL, Maria (org.). Vom Garten Eden bis zu Salomos Weinberg. Pflanzen der Bibel. Stuttgart: Katholisches Bibelwerk, 2018. p. 97-98.

MÜLLER TRUFAUT, Susanne. Weltenbaum. In: Das wissenschaftliche Bibellexikon im Internet. 2007, p. 1-8. Disponível em: http://www. wibilex.de. Acesso em: 14 maio 2021.

MUSSELMANN, Lytton John. A Dictionary of Bible Plants. Cambridge: University Press, 2012.

RIEDE, Peter. Palme. In: Das wissenschaftiche Bibellexikon im Internet. 2018, p. 1-7. Disponível em: http://www.wibilex.de. Acesso em: 14 maio 2021.

RIEDE, Peter. Weihrauch. In: Das wissenschaftliche Bibellexikon im Internet. 2019, p. 1-6. Disponível em: http://www.wibilex.de. Acesso em: 14 maio 2021.

RIEDE, Peter. Zeder. In: Das wissenschaftliche Bibellexikon im Internet. 2017, p. 1-7. Disponível em: http:/www.wibilex.de. Acesso em: 14 maio 2021.

SCHMELTER, Denis. Maulber-Feige. In: HÄUSL, Maria (org.). Vom Garten Eden bis zu Salomos Weinberg. Pflanzen der Bibel. Stuttgart: Katholisches Bibelwerk, 2018. p. 99-100.

SCHOENBORN, Ulrich; WELTEN, Peter. Kulturpflanzen. In: CRÜSEMANN, Frank; HUNGAR, Kristian; JANSSEN, Claudia; KESSLER, Rainer; SCHOTTROFF, Luise (org.). Sozialgeschichtliches Wörterbuch zur Bibel. Gütersloh: Gütersloher Verlagshaus, 2009a. p. 322-325.

SCHOENBORN, Ulrich; WELTEN, Peter. Wildpflanzen. In: CRÜSEMANN, Frank; HUNGAR, Kristian; JANSSEN, Claudia; KESSLER, Rainer; SCHOTTROFF, Luise (org.). Sozialgeschichtliches Wörterbuch zur Bibel. Gütersloh: Gütersloher Verlagshaus, 2009b. p. 652-655. 
SCHÜTTE, Inga Maria. Dattelpalme. In: HÄUSL, Maria (org.). Vom Garten Eden bis zu Salomos Weinberg. Pflanzen der Bibel. Stuttgart: Katholisches Bibelwerk, 2018. p. 77-78.

SWARS, Theresia. Echte Feige. In: HÄUSL, Maria (org.). Vom Garten Eden bis zu Salomos Weinberg. Pflanzen der Bibel. Stuttgart: Katholisches Bibelwerk, 2018. p. 81-82.

TAL, Alon. All the Trees of the Forest. Israel's Woodlands from the Bible to the Present. New Haven; London: Yale University Press, 2013. VÖGELI-PAKKALA, Christine. Speise/Speisezubereitung. In: Das wissenschaftliche Bibellexikon im Internet. 2018, p. 1-18. Disponível em: http://www.wibilex.de. Acesso em: 14 maio 2021.

ZOHARY, Michael. Pflanzen in der Bibel. 2. Ed. Stuttgart: Calwer, 1986. 